\title{
Corrosion Performance of Al-Si-Cu Hypereutectic Alloys in a Synthetic Condensed Automotive Solution
}

\author{
Hamilta de Oliveira Santos ${ }^{\mathrm{a}}$,Fernando Morais dos Reis ${ }^{\mathrm{a}, \mathrm{b}}$, Clarice Terui Kunioshi, \\ Jesualdo Luiz Rossi ${ }^{\text {a }}$ Isolda Costa ${ }^{\text {a* }}$ \\ anstituto de Pesquisas Energéticas e Nucleares, IPEN/Corrosion Laboratory \\ P. O. Box 11049, Pinheiros, 05422-970 São Paulo, Brazil \\ ${ }^{\mathrm{b}}$ Chemetall do Brasil Ltda \\ Avenida Fagundes de Oliveira, 190, Diadema, 09950-907 São Paulo, Brazil
}

Received: November 23, 2003; Revised: December 28, 2004

\begin{abstract}
In this investigation the corrosion resistance of four Al-Si hypereutectic alloys in a solution typical of condensate from automotive fuel combustion products, and referred to here as synthetic condensed automotive solution, has been studied. Three commercial alloys that are used for cylinder liners, and a laboratory made alloy, were studied by electrochemical impedance spectroscopy and measurements were taken after increasing times of immersion in this solution. Comparison of the electrochemical response of the four alloys in the corrosive solution was carried out. Although the mechanisms by which the four alloys corroded were similar, the results indicated differences in corrosion resistances of these alloys, and these differences could be related to their microstructures. The laboratory prepared alloy showed increased susceptibility to pitting corrosion compared to the commercial alloys. The surfaces of the alloys were examined, before and after the corrosion test, by scanning electron microscopy and analyzed by energy dispersive spectroscopy. The results indicated preferential attack of the aluminium matrix phase in all the alloys. The alloy with higher copper content and prepared by spray forming was more susceptible to pitting compared to the other alloys. The EIS response at low frequencies indicated a diffusion-controlled process, probably that of oxygen to the alloy interface.
\end{abstract}

Keywords: Al-Si hypereutectic alloys, cylinder liners, electrochemical impedance spectroscopy, corrosion behavior

\section{Introduction}

The increasing demand from many industries for improved properties in materials has stimulated the development of new materials. For the automotive industry, the properties most required are reduced weight, low thermal expansion coefficient and excellent mechanical properties; mainly wear resistance at high temperatures. In this context, various new materials such as the Al-Si alloys have been considered. Of particular interest are the $\mathrm{Al}-\mathrm{Si}-\mathrm{Cu}$ alloys with hypereutectic compositions, due to their optimum wear resistance. This is a consequence of the large volumetric fraction of primary silicon phase in the alloy ${ }^{1-5}$. In spite of the optimum properties of hypereutectic Al-Si-Cu alloys, it was only with technological advances, enabled by the spray forming process, that its properties were optimised ${ }^{2}$.

$\mathrm{Al}-\mathrm{Si}-\mathrm{Cu}$ hypereutectic alloys produced by spray forming have optimum mechanical properties due to a fine and homogeneous distribution of the primary silicon phase in the aluminium matrix ${ }^{5}$. These are light materials with high wear resistance, and this particular property is important for some motor parts, such as cylinder liners. In fact, spray formed Al-Si-Cu hypereutectic alloys have been recently used for the manufacture of cylinder liners where wear resistance is essential. Further, these alloys are light, have low thermal expansion coefficient, oxidation resistance at high temperatures and high hardness.

Despite the excellent mechanical and physical properties of the Al-Si-Cu hypereutectic alloys, their corrosion resistance in aggressive environments is not yet well known. In recent years some work has been carried out to evaluate the corrosion resistance of these alloys in alcoholic fuels ${ }^{6,7}$. Studies to determine the corrosion resistance of these alloys in corrosive electrolytes, that simulate the environments to which these alloys are usually exposed, are still needed. The purpose of this investigation is to evaluate the corrosion resistance of four hypereutectic $\mathrm{Al}-\mathrm{Si}-\mathrm{Cu}$ alloys; three produced by spray forming and one by conventional metallurgy, in an electrolyte with composition typical of condensates obtained from fuel combustion.

\section{Materials and Methods}

Table 1 shows the chemical composition of the Al-Si-Cu hypereutectic alloys. Alloy 1 was made in the laboratory and alloys 2 to 4 were commercially produced. Alloys 1 to 3 were made by spray forming and alloy 4 was prepared by conventional metallurgy.

\section{Test Medium}

An electrolyte with chemical composition typical of a condensate of gases from petrol fuel combustion, referred to here as condensed synthetic automotive solution (CSAS) was used in this study. CSAS consisted of ammonium nitrate $\left(0.077 \mathrm{~g} \mathrm{~L}^{-1}\right)$, ammonium sulphate (1.017 $\left.\mathrm{g} \mathrm{L}^{-1}\right)$, potassium chloride $\left(0.1345 \mathrm{~g} \mathrm{~L}^{-1}\right)$, ammonium hydroxide $\left(0.33 \mathrm{~mL} \mathrm{~L}^{-1}\right)$ and $1 \mathrm{M}$ hydrochloric acid $\left(5.8 \mathrm{~mL} \mathrm{~L}^{-1}\right)^{8}$. The $\mathrm{pH}$ of this solution was 3.3 and its conductivity approximately $4000 \mathrm{mS}$.

\section{Methods}

The corrosion behavior of the hypereutectic alloys in CSAS was evaluated by electrochemical impedance spectroscopy (EIS) after increasing times of immersion and by potentiodynamic polarization measurements after 1 day of immersion. A three-electrode cell ar- 
rangement was used for the electrochemical measurements, with a platinum wire and a saturated calomel electrode (SCE) as the counter and reference electrodes, respectively. The working electrodes of the four hypereutectic alloys were prepared by cold resin (epoxy) mounting and electrically connected to a copper wire. The electrode surfaces were prepared by grinding with silicon carbide paper up to grade \#2000, followed by polishing with diamond paste $1 \mu \mathrm{m}$, rinsing with alcohol and drying in a hot air stream.

EIS measurements were carried out with a 1260 Solartron frequency response analyser coupled to a Solartron 1287 potentiostat. All EIS measurements were performed in the potentiostatic mode and at the open circuit potential, $E_{\text {ocp }}$. The amplitude of the perturbation signal was $10 \mathrm{mV}$, and the frequency range from $10^{5}$ to $5 \times 10^{-3} \mathrm{~Hz}$, with 6 points per decade. The electrolyte was quiescent, naturally aerated and at $20 \pm 2{ }^{\circ} \mathrm{C}$. The electrochemical impedance measurements were made at test times that increased from 1 day until 6 days of immersion. All the tests were carried out in triplicate.

Potentiodynamic polarization measurements were carried out with a Solartron 1287 potentiostat coupled to a computer, in the potential range from the open circuit potential $\left(E_{\text {ocp }}\right)$ up to $1500 \mathrm{mV}$ (SCE) or to a limiting current density of $10^{-1} \mathrm{Acm}^{-2}$, at a scan rate of $1 \mathrm{mV} / \mathrm{s}$.

Table 1. Chemical composition (weight \%) of hypereutectic Al-Si alloys obtained by atomic absorption spectroscopy and gravimetry $(\mathrm{Si})$.

\begin{tabular}{ccccccc}
\hline Alloy & $\mathrm{Si}$ & $\mathrm{Mg}$ & $\mathrm{Ni}$ & $\mathrm{Cu}$ & $\mathrm{Fe}$ & $\mathrm{Al}$ \\
\hline 1 & 26.64 & 0.02 & 0.006 & 5.20 & 0.19 & Balance \\
2 & 23.19 & 1.00 & 0.960 & 2.70 & 0.19 & Balance \\
3 & 20.76 & 1.10 & 0.010 & 4.00 & 0.21 & Balance \\
4 & 16.13 & 0.64 & 0.040 & 5.00 & 0.49 & Balance \\
\hline
\end{tabular}
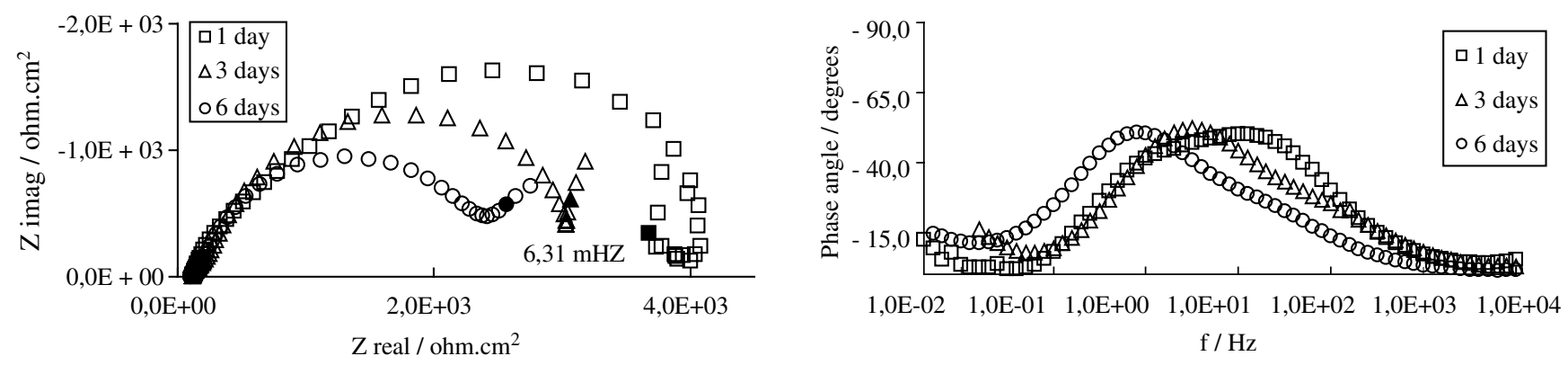

(a)
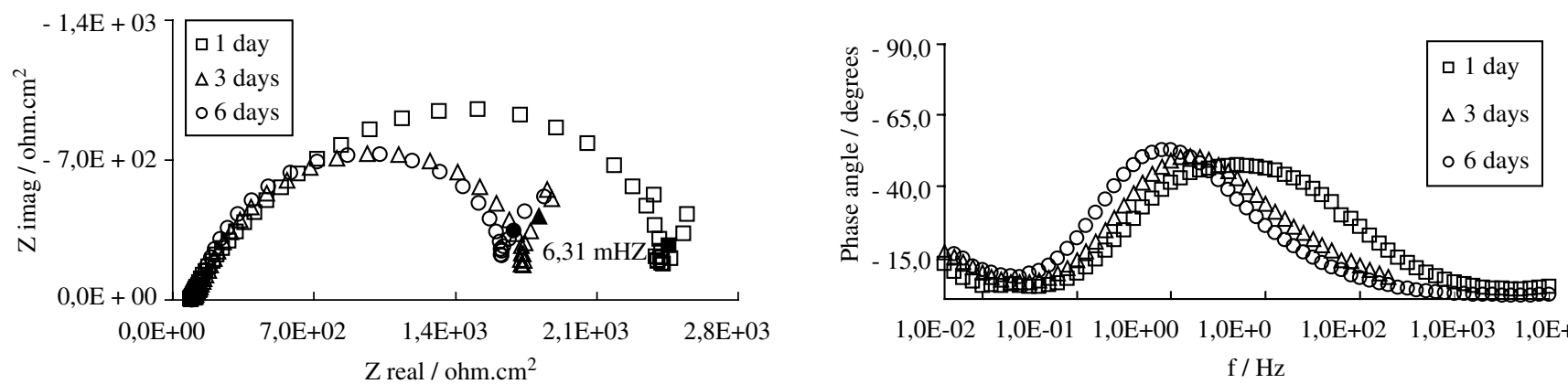

$1,0 \mathrm{E}-02 \quad 1,0 \mathrm{E}-01 \quad 1,0 \mathrm{E}+00 \quad 1,0 \mathrm{E}+0 \quad 1,0 \mathrm{E}+02 \quad 1,0 \mathrm{E}+03 \quad 1,0 \mathrm{E}+04$ $\mathrm{f} / \mathrm{Hz}$

\section{Results and Discussion}

Figures 1 and 2 show the evolution in the EIS results of the four alloys with time of immersion.

The Bode phase diagram of alloy 1 after 1 day of immersion in CSAS suggests three time constants. These are indicated by two peaks in the frequency range from $100 \mathrm{~Hz}$ to $1 \mathrm{~Hz}$, and the increase in the phase angle, after a minimum, at low frequencies, suggesting three electrochemical processes in the test solution. The results of alloy 2 after 1 day of immersion suggests that the two-time constants at medium frequencies $(10 \mathrm{~Hz}$ to $1 \mathrm{~Hz})$ interact, as indicated by the large peak in the Bode phase diagram. For alloy 1, after 1 day of immersion, the phase angle peak at high frequencies decreases with time and it practically disappears in the diagrams of alloy 2, after 3 or more days of immersion. This suggests that the contribution of this process to the electrochemical response of the system gradually decreases. Another common characteristic in the Bode diagrams is the displacement of the second phase angle peak to lower frequencies as the time increases, indicating a decrease in the kinetics of this process. This time constant is probably related to charge transfer processes.

Nyquist diagrams for alloys 1 and 2 show a depressed capacitive loop from the medium to low frequency region. Nyquist diagrams of alloy 1 show also a steady decrease of impedance with immersion time, while a major decrease of impedance was de tected for alloy 2 between 1 and 3 days of immersion. However for alloy 2, only a slight decrease occurred after 3 or more days of immersion. In the Nyquist diagrams, a straight line is seen at low frequencies (below $20 \mathrm{mHz}$ ).

Similar responses were obtained for alloys 2 to 4 , all showing a large peak after 1 day of immersion, a major decrease in impedance between 3 and 5 days of immersion and dislocation of the second peak to lower frequencies. The evolution of the peak at higher frequencies (faster kinetics) was similar for all four alloys, showing a marked decrease between 1 and 3 days of immersion.

(b)

$$
\text { (b) }
$$

Figure 1. EIS results for hypereutectic Al-Si-Cu alloys at increasing immersion periods in naturally aerated CSAS, showing Nyquist and Bode phase diagrams for: a) alloy 1 ; b) alloy 2 . 

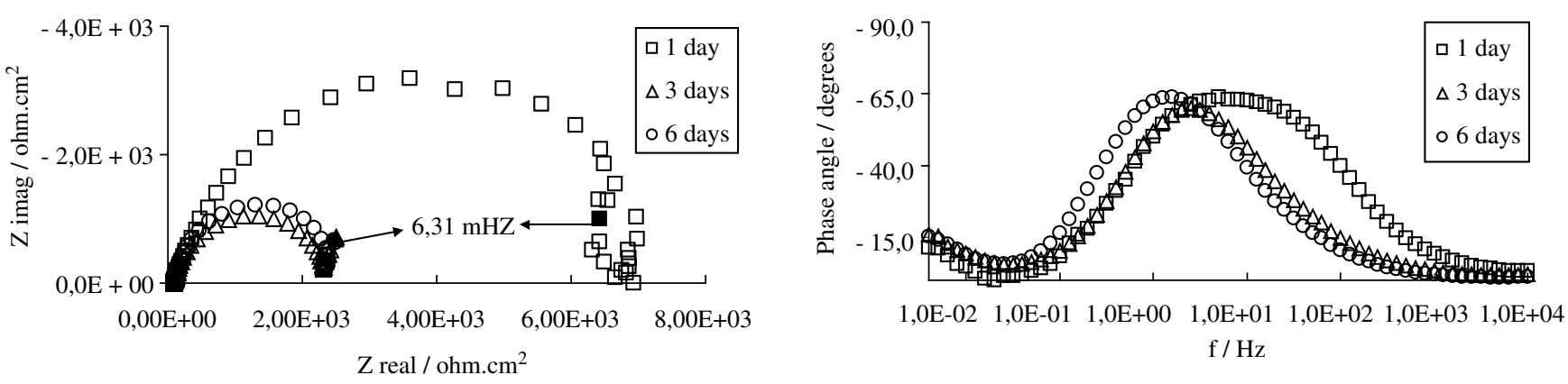

(a)
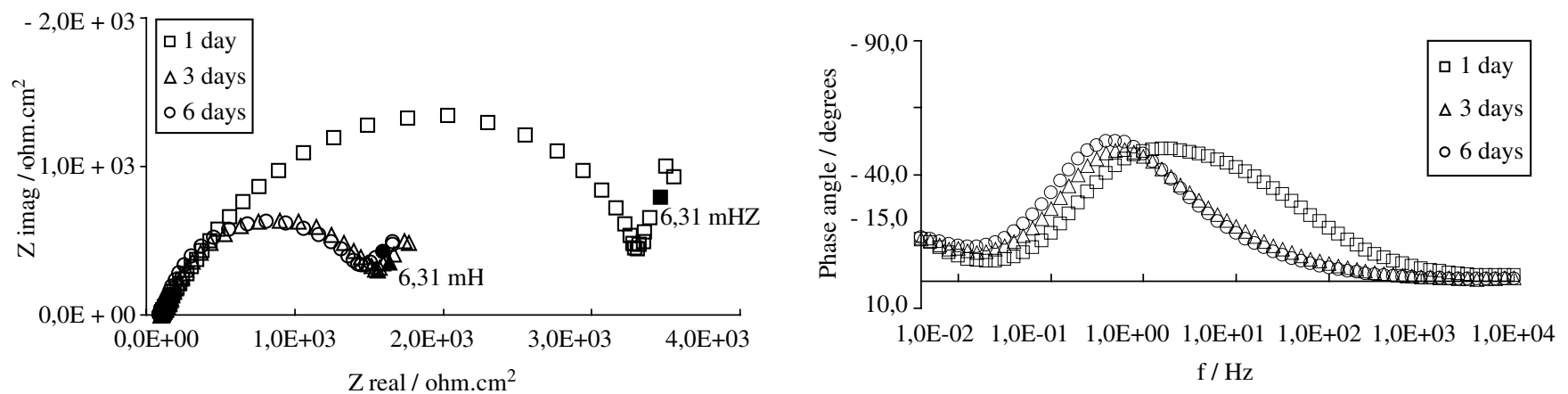

(b)

Figure 2. EIS results for hypereutectic Al-Si-Cu alloys in naturally aerated CSAS at increasing immersion periods, showing Nyquist and Bode phase diagrams for: a) alloy 3 ; b) alloy 4 .

It has been suggested that corrosion of Al-Si hypereutectic alloys starts at the matrix/precipitate interface ${ }^{9}$. These precipitate particles were rich in $\mathrm{Al}$ and $\mathrm{Cu}$, and could therefore be intermetallic $\mathrm{CuAl}_{2}$. Considering that the electrical conductivities of $\mathrm{Al}$ $\left(3.77 \times 10^{7} \mathrm{ohm}^{-1} \mathrm{~m}^{-1}\right)$ and $\mathrm{Cu}\left(5.98 \times 10^{7} \mathrm{ohm}^{-1} \mathrm{~m}^{-1}\right)$ are higher than that of $\mathrm{Si}\left(1 \times 10^{3} \mathrm{ohm}^{-1} \mathrm{~m}^{-1} \mathrm{~A} / \mathrm{cm}^{2}\right)$, and that the hydrogen evolution reaction is more polarized on $\mathrm{Al}\left(i_{\mathrm{o}}\right.$ of approximately $\left.10^{-10} \mathrm{~A} / \mathrm{cm}^{2}\right)$ than on $\mathrm{Cu}\left(i_{\mathrm{o}} \text { around } 10^{-7} \mathrm{~A} / \mathrm{cm}^{2}\right)^{10}$, it is likely that the cathodic hydrogen evolution reaction occurs on the copper rich intermetallic precipitates. This last reaction partially balances the anodic reaction, which is the dissolution of the $\mathrm{Al}$ matrix, in the acidic test solution. This in turn leads to corrosion at the matrix/intermetallic precipitate interface as a result of galvanic effects between the two phases. Moreover, the active dissolution of aluminium (matrix) can be also partly balanced by the following reaction ${ }^{9}$ :

$$
\mathrm{Si}+4 \mathrm{H}^{+}+4 \mathrm{e} \rightarrow \mathrm{SiH}_{4}
$$

Due to the low $\mathrm{pH}$ (3.3) of the test solution, the oxygen reduction reaction is not expected to contribute to the overall cathodic reaction rate. However, the EIS response at low frequencies suggests a diffusion-controlled process and this could be related to the reaction:

$$
\mathrm{O}_{2}+4 \mathrm{H}^{+}+4 \mathrm{e} \rightarrow 2 \mathrm{H}_{2} \mathrm{O}
$$

This reaction is controlled by oxygen diffusion to the metallic interface.

Figure 3 shows scanning electron micrographs of the hypereutectic $\mathrm{Al}-\mathrm{Si}-\mathrm{Cu}$ alloys after 6 days of immersion in the naturally aerated electrolyte (CSAS). The numbers indicated the various phases present in the alloys.

Pitting was only seen on alloy 1 , confirming the results of a previous work that suggested higher pitting susceptibility of this alloy ${ }^{9}$. Selective corrosion attack of the $\mathrm{Al}$ matrix occurred in all the hypereutectic alloys, and the primary silicon phase was not attacked. The particles of the primary silicon phase emerging from the matrix phase can be seen in Figure 3. Reaction (1) is considered to take place at high rates on this phase. The steady supply of hydrogen ions from the test solution $(\mathrm{pH}=3.3)$ and the high volume fraction of the primary silicon particles in the alloys, seen in Figure 3, increase the rate of this reaction. The surface of alloy 4 , which was prepared by conventional metallurgical processes, shows preferential attack on the aluminium matrix phase (Figure 3d), mainly at the matrix-primary silicon phase interface, and the latter phase is intact. Corrosive attack of the eutectic also occurred.

The electrochemical process occurring at high rates (response at higher frequencies) is probably due to charge transfer processes associated to reaction (1). The process linked to the second peak in the Bode diagrams is due to anodic dissolution of the matrix. This last reaction can be balanced by the hydrogen evolution reaction on the intermetallic particles, and by reactions (1) and (2). The EIS results suggest that the contribution of the process at high rates decreases with immersion time. This is probably due to the reaction of silicon particles with hydrogen ions forming silicon hydride, according to (1). The increased contribution of this process on alloy 1 , compared to that on the other alloys, as indicated in the Bode phase diagrams, can be attributed to the larger volume fraction of the primary silicon phase in alloy 1 , requiring longer periods for reaction (1) to reach completion.

The EIS spectra of all the alloys also show similarities in the process that occurs at medium frequencies (around $1 \mathrm{~Hz}$ ). The kinetics of this process decreases as immersion time increases, mainly between 1 day and 3 days, and is quite steady between 3 and 5 days. This is a common feature for all the alloys. It is therefore reasonable to presume that it is related to charge transfer processes associated with 


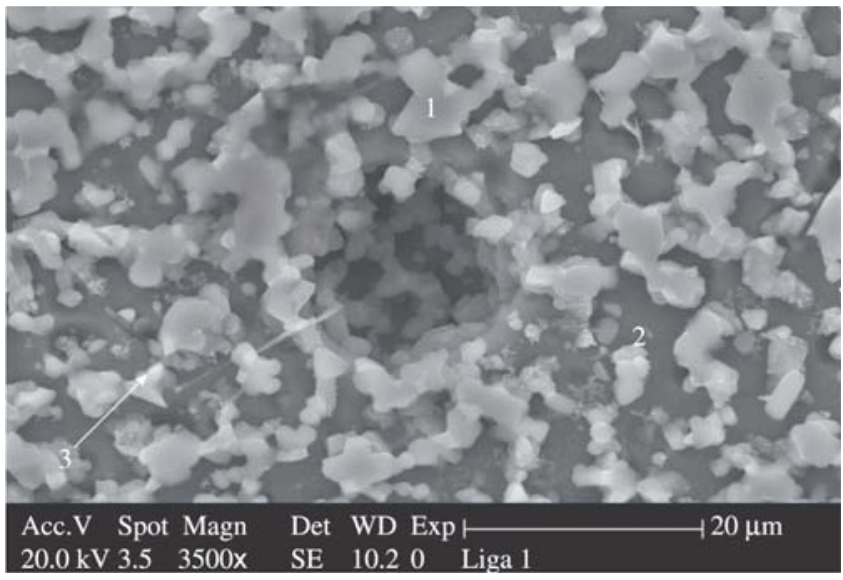

(a)

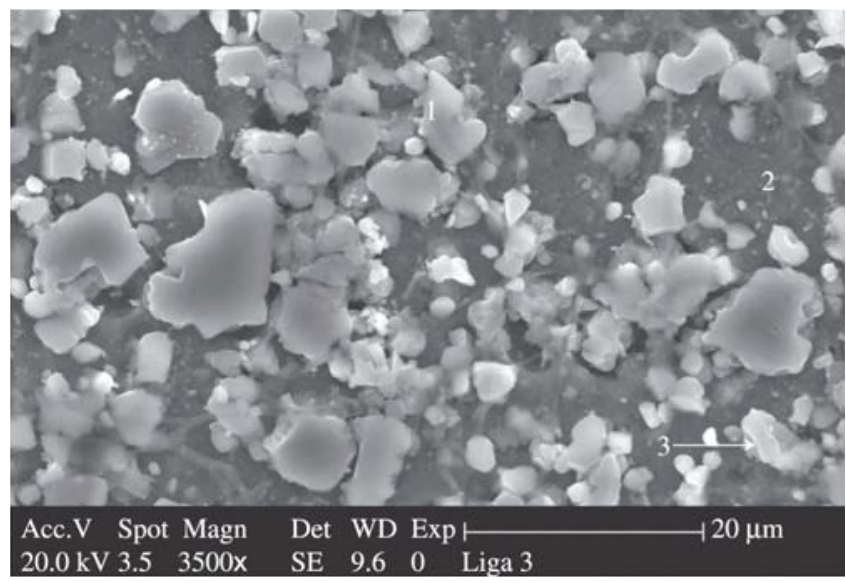

(c)

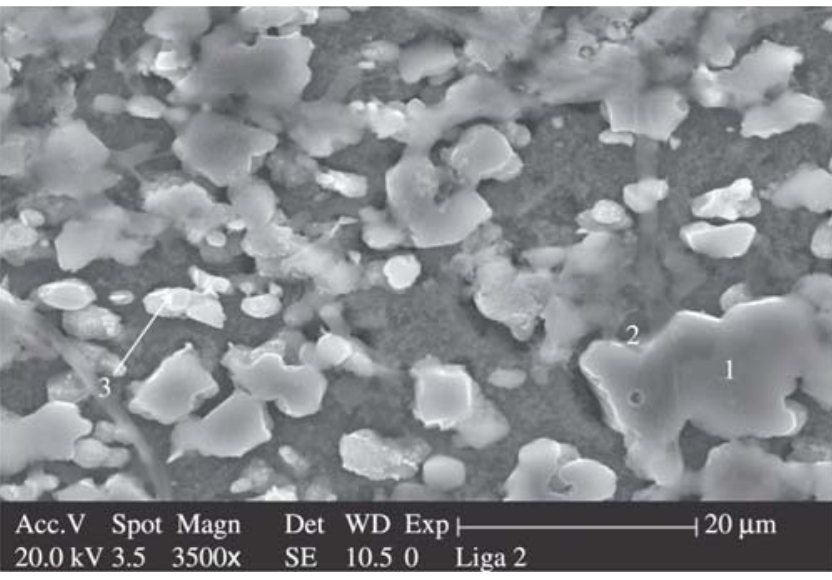

(b)

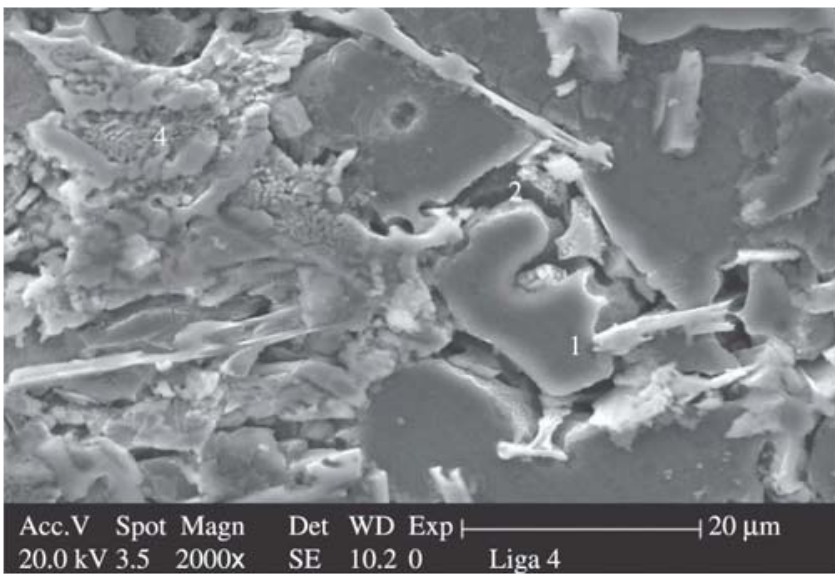

(d)

Figure 3. SEM micrographies of Al-Si-Cu hypereutectic alloys, after 6 days of immersion in naturally aerated CSAS: a) alloy 1; b) alloy 2 ; c) alloy 3 ; d) alloy 4 . Numbers indicate the phases in the alloys and correspond to: (1) primary silicon phase, (2) matrix, (3) copper rich phase, (4) eutectic.

active dissolution of the $\mathrm{Al}$ rich matrix phase. Further, the decrease in kinetics of the anodic process with time, resulting from the conversion of $\mathrm{Si}$ to $\mathrm{SiH}_{4}$, would also decrease the overall cathodic reaction rate, and consequently the dissolution (anodic) rate.

The EIS data at low frequencies indicate similar responses in all the alloys and it is probably due to Faradaic processes. The results suggest a diffusion-controlled reaction that can be linked to oxygen transport to the interface, according to reaction (2).

The potentiodynamic polarization curves, (results not presented in this work), indicated higher pitting susceptibility of alloy 1 compared to the other alloys. This increased susceptibility to pitting can be related to the higher copper content in this alloy, leading to higher volume fraction of copper rich intermetallic precipitates in this alloy. This however needs further investigation.

\section{Conclusions}

The corrosion behavior of four Al-Si-Cu hypereutectic alloys in a synthetic solution simulating a condensate from automotive fuel combustion products has been determined by electrochemical impedance spectroscopy. The results indicated preferential attack of the aluminium matrix phase in all the alloys. The alloy with higher copper content and prepared by spray forming was more susceptible to pitting compared to the other alloys. A diffusion-controlled process was indicated in the EIS response at low frequencies, due probably to oxygen transport to the metallic interface.

\section{References}

1. Socker P, Rückert F, Hummert K. The new aluminium-silicon cylinder barrel technology for die-cast aluminium crankcases. MTZ Motortechnische Zeitschrift. 1997; 58(9):16-19.

2. Staley JT, Lege DJ. Advances in aluminium alloy products for structural applications in transportation. J. Physique IV, Colloque C7, supplément au Journal de Physique III, 1993; 3:179-190.

3. Estrada JL, Duszcyk J. Characteristics of rapidly solidified Al-Si-X preforms produced by the Osprey process. J. Mat. Sci. 1990; 25:1381-1391.

4. Estrada JL, Juarez F, Lavernia EJ. Microstructure analysis of the alloy A390 and the $\mathrm{Al}-\mathrm{Si}$ (308) MMC processed by atomization and deposition. Advances in Powder Metallurgy and Particulate Materials 1997; 1:2-61 a 2-70.

5. Anand S, Srivatsan TS, Wu Y, Lavernia EJ. Processing, microstructure and fracture behavior of a spray atomized and deposited aluminium-silicon alloy. Journal of Materials Science 1997; 32:2835-2848.

6. Traldi SM, Rossi JL, Costa I. Corrosion of spray formed Al-Si-Cu alloys in ethanol automobile fuel. Key Engineering Materials 2001; 189-191:352357. 
7. Traldi SM, Rossi JL, Costa I. An electrochemical investigation of the corrosion behavior of $\mathrm{Al}-\mathrm{Si}-\mathrm{Cu}$ hypereutectic alloys in alcoholic environments. Revista de Metalurgia Supplemento S 2003; 86-90.

8. Gozzi DS, Santos HO, Kunioshi CT, Rossi JL, Costa I. Correlation pittingmicrostructure of Al-Si-Cu hypereutectic. Proceedings of the Brazilian
Society of Microscopy and Microanalysis-SBMM 2002; Curitiba. CDRom.

9. Fontana MG, Corrosion Engineering. 1987; McGraw-Hill, $3^{\text {rd }}$ edition; p. $454-457$

10. Gentil V. Corrosion. 1996; LTC-Livros tecnicos e cientificos Ed. S.A., $3^{\text {rd }}$ edition, p. 345 (In Portuguese). 